Original Article

\title{
RESEARCH AND DEVELOPMENT OF DIAZEPAM SOLID DISPERSION POWDER USING NATURAL POLYMERS
}

\author{
UDITI HANDA' ${ }^{1}$ KAMAL SAROHA ${ }^{2}$
}

${ }^{1}$ Guru Gobind Singh College of Pharmacy, Yamuna Nagar 135001, Haryana, India, ${ }^{2}$ Department of Pharmaceutical Sciences, Institute of Kurukshetra University, Kurukhetra 136119, India

Email: uditipharmacist@gmail.com

Received: 15 Jun 2018, Revised and Accepted: 03 Aug 2018

\section{ABSTRACT}

Objective: The objective of this study was to enhance the solubility and dissolution rate of a poorly water-soluble drug by solid dispersion (SD) technique, in order to conduct an investigation of the effect of these natural hydrophilic polymers on release mechanism from SD.

Methods: The SD of diazepam (DZM) were prepared by using modified sodium alginate (SA) and modified guar gum (GG) in different drug: polymer ratios (1:1 and 1:2) by using physical mixture method (PM) and fusion method (FM). Further, the formulations were characterized for calibration curve, Fourier transforms infrared spectroscopy (FTIR) studies, \% age practical yield, drug content estimation, solubility studies, dissolution studies.

Results: The pure drug and SD were characterized by pre and post-formulations studies. The \%age practical yield ranged from $92.9 \pm 0.25$ to $49 \pm 0.57 \%$, and the drug content estimation ranged from $99.34 \pm 0.40$ to $65.25 \pm 0.25 \%$. The FTIR studies shown that the compatibility between pure drug and natural polymers was stable. All the SD showed improved solubility as compared to the pure drug (PD). SD prepared with modified SA $(1: 2)$ by PM and FM shown the huge enhancement of solubility and dissolution rate of the DZM. This can be specific to the improvement in wettability and dispersibility, as well as enhances the drug amorphous fraction.

Conclusion: On the basis of the research study, the SD technique shows the enhancement in the solubility of poorly water-soluble drug using natural polymers. SD containing natural polymers prepared with PM and FM shown the remarkable improvement in the release outline compared with PD, DZM.

Keywords: Diazepam, Solid dispersions, Natural polymers, FTIR, Methods

(c) 2018 The Authors. Published by Innovare Academic Sciences Pvt Ltd. This is an open access article under the CC BY license (http://creativecommons.org/licenses/by/4.0/) DOI: http://dx.doi.org/10.22159/ijap.2018v10i5.27975

\section{INTRODUCTION}

To improve the therapeutic efficacy of poorly water-soluble drugs through oral administration, which often shows the poor bioavailability due to their slow and irregular levels of the absorption at the site of therapeutic action. Drugs suffered from dissolution rate limited G. I. T absorption generally shows a reduction in particle size of the formulation due to the increase in the surface area which automatically improves the dissolution and bioavailability. However, micronizing of the drugs leads to the formation of a bunch of particle in cluster form, which results in poor wettability of the drug. To overcome these problems, SD of poorly water-soluble drug with water-soluble polymers is prepared to enhance the solubility as well as dissolution profiles [1-3].
DZM, as the most representative benzodiazepine, is widely used as anticonvulsant, anxiolytic, sedative agent, hypnotic, muscle relaxant and is also very useful in suppressing febrile and epileptic convulsions $[4,5]$. It is used in alcohol withdrawal symptoms, or muscle spasms and sometimes it is used to treat seizures with other medications [6-8]. As benzodiazepines, DZM is a positive allosteric modulator of the Gamma-aminobutyric acid type A receptors (GABAA). The binding of DZM to the GABAA receptor increases the affinity of the receptor, thereby increasing the opening frequency of GABAA receptor, resulting in an increased influx of $\mathrm{Cl}$-ion into neurons which prevents the further excitation of the cell. The excitability of the neurons is therefore diminished $[4,6,7,9]$.

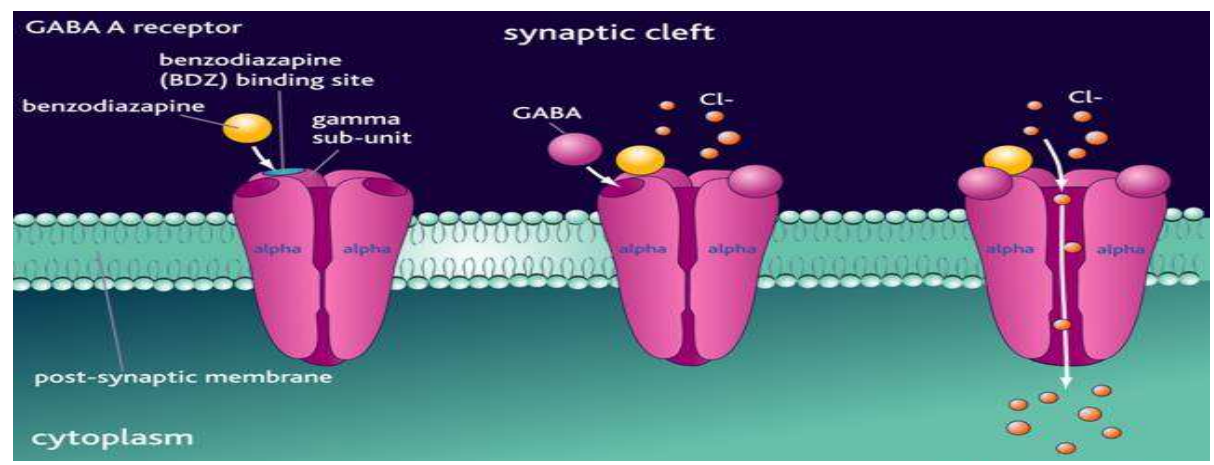

Fig. 1: Schematic representation of the mode of action of DZM [10]

Although parenteral therapy is the most faster way to get a rapid action, this drug administration route shows some difficulty to the patient, such as the pain, needle fear, the syringe manager, the risk of needle infection, etc., carrying disconcert and poor patient compliance. Oral immediate-release dosage forms can be a good alternative to intravenous therapy. However, DZM when 
administrated orally due to the poor aqueous solubility, it produces erratic and delayed absorption. [11-16]. The enhancement in the solubility and/or dissolution rate/bioavailability of DZM may arrive from the preparation of SD $[5,7,9]$. The increase in solubility/dissolution rate from the SD can be attributed by the merging of following different factors; particle size reduction of drug, solubilising effect on the drug by the water-soluble polymers due to improved wettability and dispersibility of the drug particles by using various hydrophilic polymers and the possible formation of a accessible dispersion that has a higher solubility resulting in rapid dissolution rate. Drug release from solid dispersions is described in several ways. Immediate release drug products allow drugs to dissolve with no intention of delaying or prolonging the dissolution or absorption of the drug [7,9].

Natural polymers were used in this research article first was SA: Due to the inherent mucoadhesive nature of alginate, it is expected that these SDs would be retained over a longer time-period in the stomach, which is the predominant absorption site of DZM, thus further extending their utility. There is an urgent need for the development of more such eco-friendly technologies keeping in view the stringent environmental regulations [17-21]. And second was GG: It is a water-soluble fibre, act as a bulk-forming laxative and is effective in promoting regular bowel movements and relieving constipation. Due to the swelling nature of the carrier, the extensive surface of the carrier is increased during dissolution, and the dissolution rate of the deposited drug is markedly enhanced. Water retention capacity of the carrier is the amount of water retained in it that indicates the ability of carrier towards hydrophilic nature. When a drug-carrier particle comes in contact with the dissolution fluid, seeping of dissolution media into the drug-polymer particle takes place, which initiates the formation of a stagnant gel layer of polymer around the particle [22-25]. The main aim of this study was to improve the solubility and dissolution rate of DZM by using natural polymers with SD technique.

\section{MATERIALS AND METHODS}

\section{Materials}

The sample of DZM was gifted from Symbiosis P'ceutical Pvt. Ltd. Kalaamb Himachal Pradesh (H. P). SA and GG was gifted by Loba Chemie Pvt. Ltd. Mumbai.

Table 1: List of materials used

\begin{tabular}{lll}
\hline Category & Material & Supplier \\
\hline Drug & Diazepam & Symbiosis P'ceutical Pvt. Ltd. Kala aam (H. P) \\
Polymer & Sodium alginate & Loba chemie pvt. ltd. Mumbai. \\
Polymer & Guar gum & Loba chemie pvt. ltd. Mumbai. \\
Solvent & Methanol & HiMedia Laboratories Pvt. Ltd., Mumbai. \\
\hline
\end{tabular}

\section{Preparation of DZM SD}

\section{Physical mixing method}

In this process, $50 \mathrm{mg}$ of DZM was weighed accurately, and physical mixtures were formulated by the mixing of drug and polymer in geometric proportions using the mortor pestle. The resultant SD was passed through a No.60-mesh sieved, stored in dessicator or airtight container until used for further studies $[16,20,21,26]$.

\section{Fusion method}

Melted the polymer (molten state) and then incorporate the drug, melted mixture was cooled and solidified rapidly in an ice bath under vigorous stirring. The final mass was crushed, pulverized and sieved by 44-mesh sieve [2, 3, 16, 20, 21, 26].

\section{Characterization of SD}

\section{Calibration curve of DZM}

\section{In methanol}

$10 \mathrm{mg}$ DZM was weighed accurately and dissolved in $100 \mathrm{ml}$ of methanol to produce a $0.1 \mathrm{mg} / \mathrm{ml}$ solution. $20 \mathrm{ml}$ of the above solution was transferred in a volumetric flask and volume was made up to $100 \mathrm{ml}$ with the distilled water. $1,2,3$, , up to $10 \mathrm{ml}$ of this solution was taken in the $10 \mathrm{ml}$ of volumetric flasks and the distilled water was added up to the mark to prepared the standard solutions. These serial dilutions were carried out from the stock solution to get different DZM concentrations. Standard solutions were then analyzed by the UV spectrophotometer at $230 \mathrm{~nm}$ and the absorbance was to be noted. Then the graph was plotted against the absorbance values v/s drug concentration and Diazepam standard curve was produced $[7,9,12,13,16,20]$.

\section{In PBS (pH6.8)}

Weighed accurately diazepam amount was dissolved in the $5 \mathrm{ml}$ methanol and diluted to the $100 \mathrm{ml}$ with the poshate buffer solution (PBS). Diluted five the above drug solution to get a stock solution having a concentration $(25 \mu \mathrm{g} / \mathrm{ml})$. Fractional of this stock solution was further diluted to $25 \mathrm{ml}$ with the buffer solution having the concentrations from $1-9 \mu \mathrm{g} / \mathrm{ml}$ to get the standard solutions. The above solutions were scanned from 200 to $400 \mathrm{~nm}$ against a blank (PBS). Standard solutions were set to prepared three times a day from the same stock solution $(25 \mu \mathrm{g} / \mathrm{ml})$ and afterward, solution was scanned to get the absorbance value (A) at 2-nm interval $[9,13,16]$.

Table 2: Composition of solid dispersions formulation

\begin{tabular}{llll}
\hline Method & Carrier & Drug: carrier ratio & Batch code \\
\hline PM & GG & $1: 1$ & F1 \\
& & $1: 2$ & F2 \\
& SA & $1: 1$ & F3 \\
FM & GG & $1: 2$ & F5 \\
& SA & $1: 1$ & F6 \\
& & $1: 2$ & F7 \\
\hline
\end{tabular}

\section{FTIR spectroscopy}

The FTIR spectral of the drug and solid dispersion in different ratios were recorded with FTIR spectrophotometer. The sample was prepared by mixing with $\mathrm{KBr}$ then compressed into disks by a hydraulic press. The disks were loaded into FTIR holder and scanned for absorbance at $4000-400 \mathrm{~cm}^{-1}$ [8].

\section{$\%$ age practical yield}

For the determination of the efficiency of any method of production, $\%$ age practical yield was calculated. SD was collected and weighed to calculate the practical yield (PY) from the following equation: $[2,3,16,20]$

PY $(\%)=[$ Practical mass $($ solid dispersion $) /$ Theoretical mass (drug+carrier) $\mathrm{x} 100]$ 


\section{Drug content estimation}

Dissolved the accurately weighed quantity of SD equivalent to $10 \mathrm{mg}$ in $10 \mathrm{ml}$ of methanol solvent. Further, $1 \mathrm{ml}$ of solution was taken and diluted suitably. The solution was then filtered through whatman filter paper. The determination of DZM content was carried out at $240 \mathrm{~nm}$ by UV-visible spectrophotometer. The \% age drug content was to be calculated using the following equation: $[16,20,21,26]$

$$
\text { Drug content }(\%)=\frac{\text { Actual amount of the drug in Solid dispersion }}{\text { Theoretical amount of the drug in Solid dispersion }} * 100
$$

\section{Solubility studies}

The flasks containing $10 \mathrm{ml}$ of PBS $(6.8 \mathrm{pH})$ and distilled water and dissolve the PD and SD in excess quantity in it. The samples were placed in a magnetic stirrer at $37^{\circ} \mathrm{C}$ for $1 \mathrm{~h}$. The solutions were analyzed by the UV-spectrophotometer [20,21,26].

\section{Dissolution studies}

The in vitro dissolution study was carried out in a paddle type Dissolution Apparatus (USP Type II). The SD containing $40 \mathrm{mg}$ equivalent DZM (fixed amount) from each formulation was calculated for dissolution profile. PBS (pH 6.8) with $900 \mathrm{ml}$ volume was used as dissolution medium, in each dissolution sink at $37{ }^{\circ} \mathrm{C}$ temperature and $100 \mathrm{rpm}$ paddle speed. The dissolution was conducted for $1 \mathrm{~h}$ and withdrawn the $5 \mathrm{ml}$ sample at predetermined intervals of 5, 10, 20, 30, 40, 50 and $60 \mathrm{~min}$. Each and every time compensated by another fresh $5 \mathrm{ml}$ buffer solution with the $5 \mathrm{ml}$ withdrawn sample. Then filtered and withdrawn dissolution sample through Whatman No.41 filter paper in a test tube. The absorbance was to be noted by scanning the dissolution samples by the UV-VIS spectrophotometer at $240 \mathrm{~nm}[2,3,16,20,21,26]$.

\section{RESULTS}

\section{DZM calibration curve}

The calibration curve of DZM was prepared in methanol and phosphate buffer (pH6.8) solution at $240 \mathrm{~nm}$, and the absorbance values at different concentrations of DZM in methanol $\mathrm{sol}^{\mathrm{n}}$ are shown in fig. 2. Values of $\mathrm{R}^{2}$ (regression coefficient) were found to be 0.996 and 0.940 .

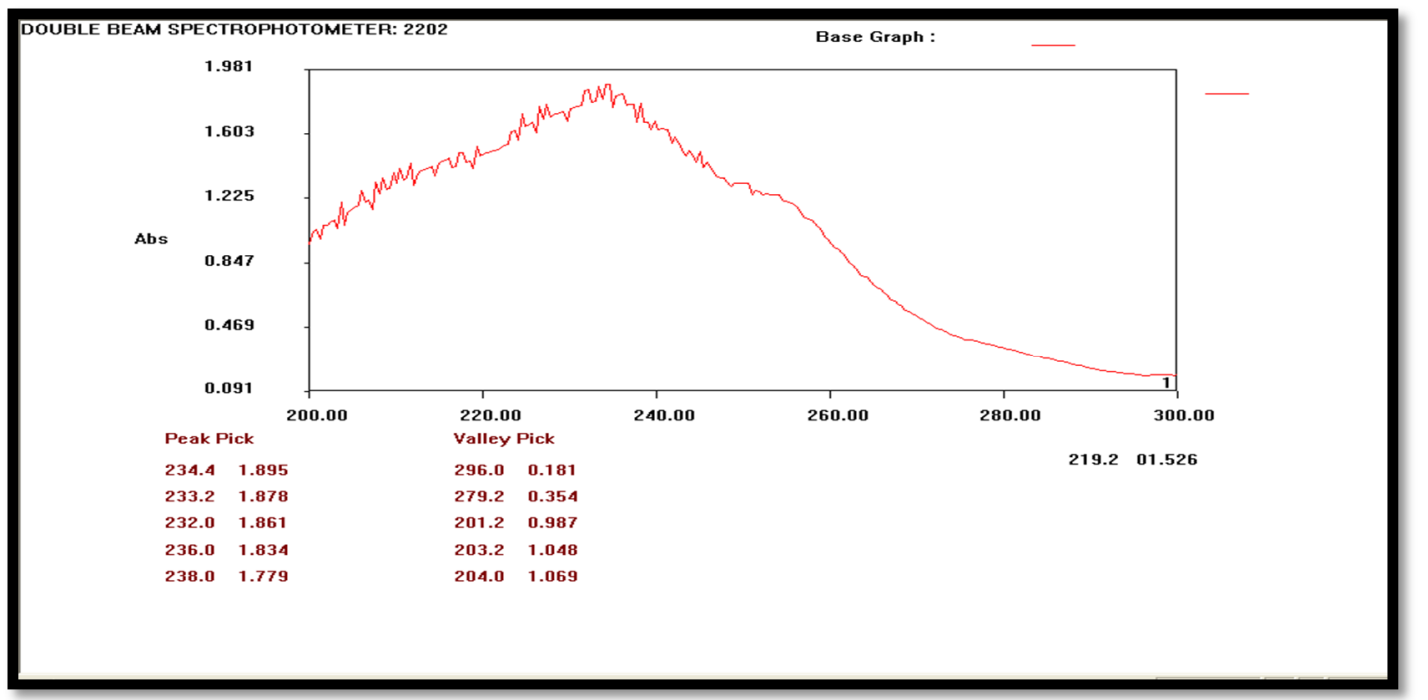

Fig. 2: $\Lambda_{\max }$ scan for DZM

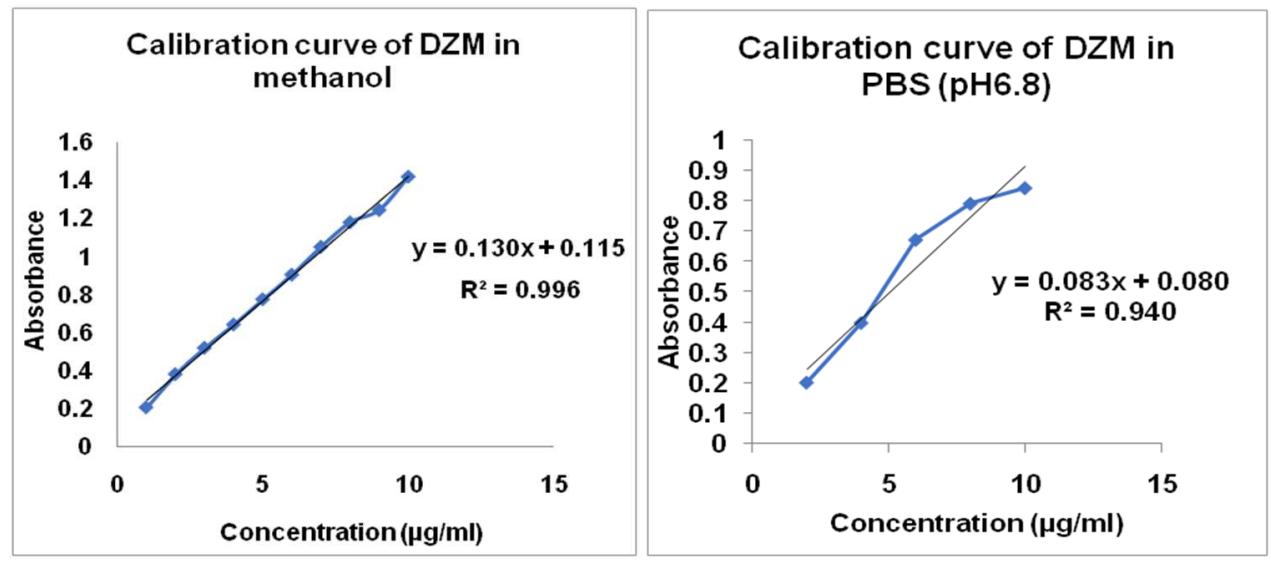

Fig. 3: Calibration curve of DZM

\section{Percentage practical yield and drug content}

Percentage practical yield of DZM SD was in the range of $92.9 \pm 0.25$ to $49 \pm 0.57 \%$. The $\%$ age yield was low for $1: 1$ of sodium alginate by fusion method and high for 1:1 of GG by PM. DZM content range of $99.34 \pm 0.40$ to $65.25 \pm 0.25 \%$ was to be found. The drug content was low for $1: 1$ of by fusion method and high for $1: 1$ of sodium alginate by physical mixing method.

\section{FT-IR studies (Drug-excipients compatibility studies)}

There was no interaction between the DZM, GG, SA and the DZM SD formulations were shown in the FT-IR spectra (fig. 4-7). 

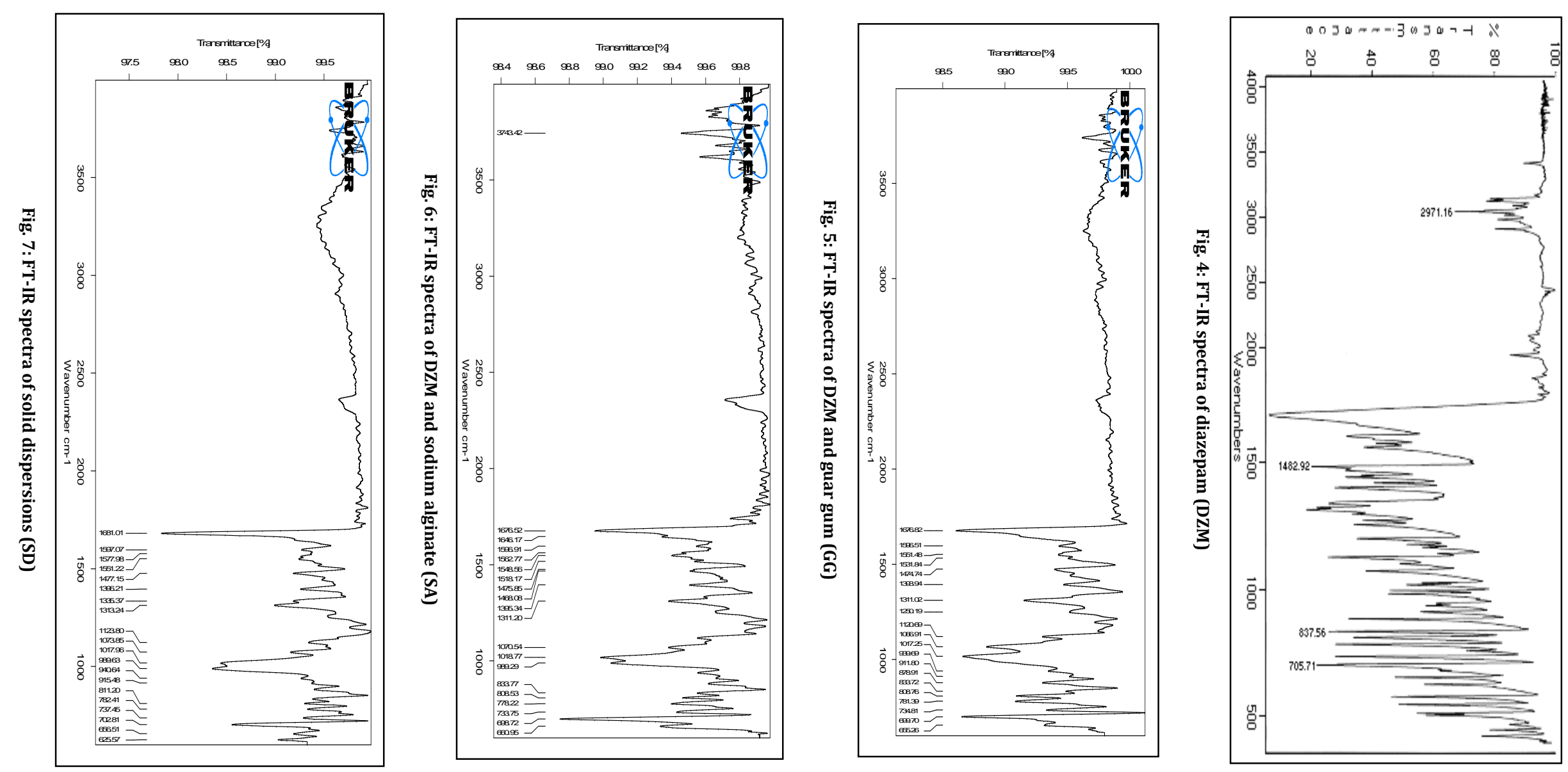

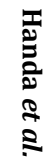

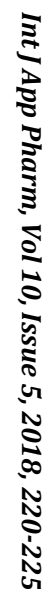


Table 3: Solubility of PD and formulations F1 to F8 in distilled water and PBS pH 6.8

\begin{tabular}{lll}
\hline Formulation batches & \multicolumn{2}{c}{ Solubility analysis (mg/ml) } \\
\cline { 2 - 3 } & \multicolumn{1}{l}{ (Distilled water) } & (PBS) (pH 6.8) \\
\hline Pure drug & $0.02 \pm .006$ & $0.0623 \pm .0001$ \\
F1 & $0.08 \pm .005$ & $0.116 \pm .0009$ \\
F2 & $0.0755 \pm .005$ & $0.115 \pm .0008$ \\
F3 & $0.116 \pm .0004$ & $0.107 \pm .0006$ \\
F4 & $0.125 \pm .004$ & $0.106 \pm .001$ \\
F5 & $0.116 \pm .0004$ & $0.103 \pm .0006$ \\
F6 & $0.067 \pm .0004$ & $0.076 \pm .0006$ \\
F7 & $0.115 \pm .0006$ & $0.106 \pm .0005$ \\
F8 & $0.106 \pm .001$ & $0.128 \pm .006$ \\
\hline
\end{tabular}

mean \pm Standard deviation, $n=6$

\section{Solubility analysis}

The DZM solubility in PBS with modified SA (1:2) by FM was found to be $0.128 \pm .006 \mathrm{mg} / \mathrm{ml}$.

\section{In vitro dissolution profile}

In $0.2 \mathrm{M}$ phosphate buffer the in vitro dissolution study of PD and all the formulations was to be carried out. Dissolution profile for various batches of SD (F1 to F8) in PBS ( $\mathrm{pH}$ 6.8) is given in fig. 8. The dissolution curve of DZM, by PM and FM are shown in above figures, from these it was concluded that the enhancement of the dissolution rate of DZM to a greater level by FM.

In case of PD only $51.51 \pm 0.32 \%$ was dissolved at the end of $1 \mathrm{hr}$ in PBS ( $\mathrm{pH}$ 6.8), SDs by PM show a release rate up to $81.58 \pm 0.23 \%$ and SDs by FM show a release rate up to $92.8 \pm 0.21 \%$ as we can see the graphical representation in fig. 8.

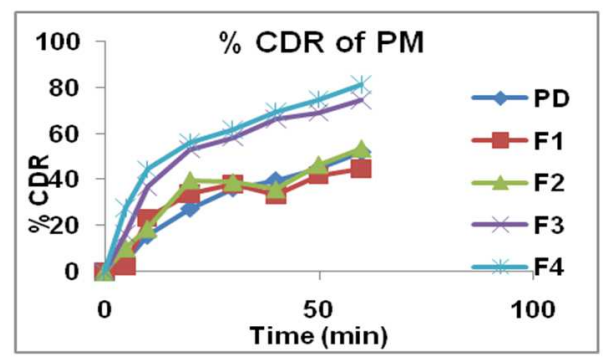

(A)

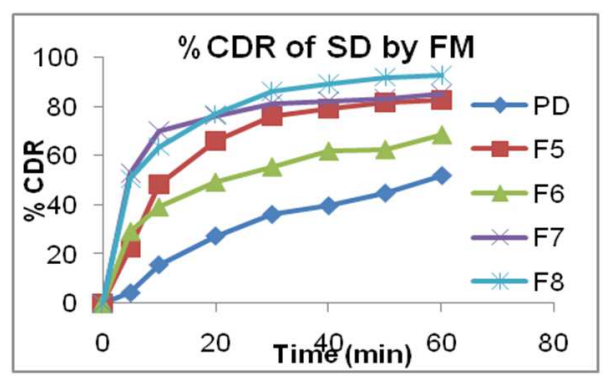

(B)

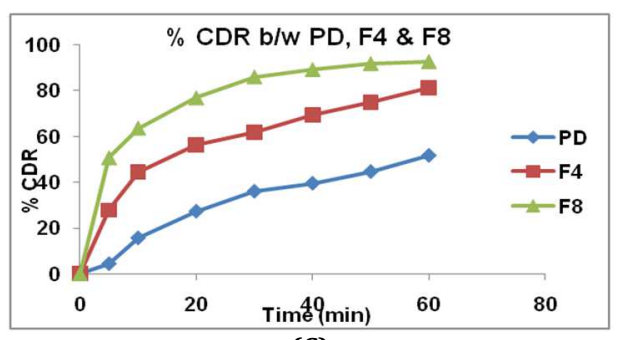

(C)

Fig. 8: (A) dissolution data of PD and DZM SD by PM (F1-F4), (B) dissolution data of PD and DZM SD by FM (F5-F8), (C) dissolution data of PD and SDs of optimized formulations batch F4 and F8

\section{DISCUSSION}

From the above observation, it was concluded that the DZM solubility was increased as a linear function of carrier concentration. All the SD showed enhanced solubility as compared to PD as shown in table 3. The observation indicated that due to the presence of the drug in the amorphous state increased the dissolution rate of DZM SD (F8) as compare to SD by PM and PD. Compared with the PD, PM, $\mathrm{FM}$, the dissolution was found to increase in the following order.

\section{Pure drug $<$ physical mixture $<$ fusion method}

The result of these dissolution data of SD by PM and FM shown the enhancement of dissolution profile as compare to PD as shown in fig.8 (C). The presence of natural polymer might increase the wettability and dissolution rate of the drug (DZM). As far as FTIR interpretation shows three signals at $3000 \mathrm{~nm}, 1442 \mathrm{~nm}$ and 837.56 $\mathrm{nm}$ was due to the-CH,-CCH (blend) and-NCO (blend) groups of the PD in fig. 4 but the spectra shown in the fig. 5 to 7 shown no signal at $3000 \mathrm{~nm}, 1442 \mathrm{~nm}$ and $837.56 \mathrm{~nm}$ which results in no interaction b/w the PD, SA, GG, SD. The evaluated data of this research work shows the improvement in the solubility, dissolution rate and also the bioavailability which was arrived from the preparation of SD. However, DZM when administrated orally due to the poor aqueous solubility, it produces erratic and delayed absorption. The study was to done to overcome these problems so that the oral pharmaceutical formulation was a good alternative to intravenous therapy.

\section{CONCLUSION}

From the above evaluation, it was inter-prated that the DZM dispersions formulated by SD technique shows the enhancement in the solubility of poorly water-soluble drug using natural polymers. FM contains the modified SA (1:2) was used to prepared SD and was the best method which improves the drug dissolution as compare to PM containing modified GG or PD. The presence work unveil that optimum level of natural hydrophilic polymers ensure rapid absorption of drug (DZM) and this was achieved by SD technique. From the evaluated data, it was concluded that the natural polymer and the ratio of drug-polymer show the enhancement in the solubility, dissolution rate as well as bioavailability of the drug (DZM) by SD technique.

\section{LIST OF ABBREVIATIONS}

$\mathrm{DZM}=$ Diazepam, $\mathrm{PM}=$ Physical mixing method, $\mathrm{FM}=$ Fusion method, GG = Guar gum, $\mathrm{SA}=$ Sodium alginate, $\mathrm{SD}=$ Solid dispersions, $\mathrm{PD}=$ Pure drug, $\mathrm{PBS}=$ Phosphate buffer solution, $\mathrm{PY}=$ Practical yield, $\mathrm{pH}=$ Negative logarithm of hydrogen ion concentration, BCS = Biopharmaceutical Classification System, GIT = Gastrointestinal tract, FTIR = Fourier transform infra-red spectroscopy, GABA = Gamma-aminobutyric acid

\section{ACKNOWLEDGEMENT}

The authors would like to thanks to Symbiosis P'ceutical Pvt. Ltd. Kala amb (H. P).

\section{AUTHORS CONTRIBUTIONS}

All the author have contributed equally

\section{CONFLICT OF INTERESTS}

The authors declare no conflict of interest to this research article 


\section{REFERENCES}

1. Chowdary KPR, Sankar Ravi K. Recent research on solid dispersions employing superdisintegrants and surfactants as a carrier. Int J Chem Sci Technol 2015;378-86.

2. Singh S, Yadav L. A review on solid dispersion. Int J Pharm Life Sci 2011;2:1078-95.

3. Kapoor B, Kaur R. Solid dispersion: an evolutionary approach for solubility enhancement of poorly water-soluble drugs. Int J Recent Adv Pharm Res 2012;2:1-6.

4. Tripathi KD. Essential of medical pharmacology. $7^{\text {th }}$ ed. Jaypee brothers medical Publication; 2013. p. 372-11.

5. Shah SN. Development and validation of simple uvspectrophotometric Method for quantitation of diazepam in api and solid dosage formulation. World J Pharm Med Res 2015;2:1-4.

6. Ada K. Properties of Diazepam (valium); 2007. p. 1-2.

7. Hadziabdic I, Elezovic A, Hadzovic S, Vehabovic M. The solubility-intrinsic dissolution rate of diazepam and inclusion complexes diazepam with 2 hydroxypropyl- $\beta$-cyclodextrin. Int J Sci Technol Soc 2013;24-35. Doi:10.11648/j.ijsts.20130101.14

8. Patel SA. Simultaneous spectrophotometric determination of diazepam and propranolol hydrochloride in tablets. Curr Res Pharm Sci 2011;1:25-30.

9. Daharwal SJ. Development and validation of UV spectrophotometric method for simultaneous estimation of diazepam and propranolol in bulk drug and its formulations. Asian J Pharm Anal 2013;3:20-3.

10. thefisheriesblog.com [Last accessed on 15 May 2018]

11. Josep ER. Use of micellar mobile phases for the chromatographic determination of clorazepate, diazepam, and diltiazem in pharmaceuticals. J Chromatographic Sci 2000;30:521-7.

12. IP. Indian Pharmacopoeia commission. Ghaziabad 2007;2:1013-4.

13. Nebojsa D Cekic, Sanela M Đorđevic, Sasa R Savic. A full factorial design in the formulation of diazepam parenteral nanoemulsions: physicochemical characterization and stability $\begin{array}{llll}\text { evaluation. Adv } & \text { Technol } & \text { 2015;69-77. }\end{array}$ Doi:10.5937/savteh1501069C

14. Manogar PG, Hari BNV, Devi DR. Emerging liquisolid compact technology for solubility enhancement of BCS class-II sDrug. J Pharm Sci Res 2011;3:1604-11.

15. Sylaja B, Srinivasan S. Experimental and theoretical investigation of spectroscopic properties of diazepam. Int J ChemTech Res 2012;4:361-76.

16. Alway B, Sangchantra R, Stewart PJ. Modeling the dissolution of diazepam in interactive lactose mixtures. Int J Pharm 1996;130:213-24.

17. Shanmugam. Natural polymers and their applications. Int J Pharm Sci Rev Res 2005;37:478-81.

18. Singh Anupama. Release behavior of drugs from various natural gums and polymers. Polim Med 2011;41:73-80.

19. FMC biopolymer. Alginate. Nova Matrix Ultrapure Biopolymer Systems; 2011. p. 1-2.

20. Howlader Md, Chakrabarty JK, Faisal KS. Enhancing dissolution profile of diazepam using hydrophilic polymers by solid dispersion technique. Int Curr Pharm J 2012;1:423-30.

21. Kaza R, Kumar AG, Charan YR. A study on the dissolution enhancement of gliclazide using natural polymers. Int J Innovative Pharm Res 2012;3:194-8.

22. Gupta A, Verma DK. Guar gum and their derivatives: a research profile. Int J Adv Res 2014;41:680-90.

23. Prasad SS, Rao KM. Synthesis and characterization of guar gumg-Poly (Acrylamidoglycolic acid) by redox initiator. Indian J Adv Chem Sci 2012;1:28-32.

24. Tripathi S, Das MK. Guar gum: present status and applications. J Pharm Sci Innovation 2013;2:24-8.

25. Shejul A, Deshmane S, Biyani K. Modified natural carrier in solid dispersion for enhancement of solubility of poorly watersoluble drugs. J Drug Delivery Ther 2014;4:111-6.

26. Kaza R, Raju YP. Dissolution enhancement of valsartan using natural polymers by solid dispersion technique. Scholars Res Library De Pharm Lett 2013;5:126-34. 